\title{
Correction factors for weight productive traits up to weaning in the Bruna dels Pirineus beef cattle breed
}

\author{
Joaquim CASellas, Jesús Piedrafita* \\ Departament de Ciència Animal i dels Aliments, Universitat Autònoma de Barcelona, \\ 08193 - Bellaterra (Barcelona), Spain
}

(Received 2 February 2001; accepted 6 March 2002)

\begin{abstract}
Correction factors for sex of the calf, birth type and age of dam have been calculated regarding birth weight (BW), weaning weight (WW) and average daily weight gain (DWG) in the Bruna dels Pirineus breed. Standard deviations were heterogeneous for the two levels of sex and homogeneous for the two levels of birth type. Therefore, multiplicative correction factors were better for the sex of the calf, whereas additive correction factors were better for birth type. An age of dam correction resulted in either homogeneous (WW and DWG) or heterogeneous (BW) standard deviations depending upon the trait considered. It was observed that in general the additive correction was better, although this correction failed to completely homogenise the standard deviations within the levels of age of the dam for the respective variables.
\end{abstract}

correction factors / beef cattle / productive traits / Bruna dels Pirineus

Résumé - Facteurs de correction des caractéristiques de poids jusqu'au sevrage dans la race à viande bovine Bruna dels Pirineus. Les facteurs de correction relatifs au sexe du veau, au type de naissance (simple ou gémellaire) et à l'âge de la mère ont été calculés pour ce qui concerne le poids à la naissance (BW), le poids au sevrage (WW) et le gain de poids moyen quotidien (DWG) dans la race Bruna dels Pirineus. Les écarts types ont été hétérogènes pour les deux niveaux correspondant au sexe, et homogènes pour les deux niveaux correspondant au type de naissance. Par conséquent, les facteurs de correction multiplicatifs ont été meilleurs pour le sexe du veau, tandis que les facteurs de correction additifs ont été meilleurs pour le type de naissance. La correction prenant en compte l'âge de la mère a entraîné des écarts types homogènes (WW et $\mathrm{DWG}$ ) ou hétérogènes (BW). En général, la correction additive a été meilleure, bien que cette correction n'ait pas rendu complètement homogène les écarts types dans les niveaux d'âge de la mère pour les variables étudiées.

facteurs de correction / bovins à viande / caractéristiques de poids / Bruna dels Pirineus

\footnotetext{
* Correspondence and reprints

Tel.: 3493 5811399; fax: 3493 5812006; e-mail: Jesus.Piedrafita@uab.es
} 


\section{INTRODUCTION}

Bruna dels Pirineus, a beef type breed selected from the old Brown Swiss, similar to the American Braunvieh, is used for extensive beef cattle production in the geoclimatic and management conditions of Catalonia (Spain). Historically, weaning weight and daily weight gain until weaning have been considered as important components of on farm testing programs, since the weaned calf represents the main source of income for breeders and farmers $[12,17$, 20]. These traits have been used as an indication of the potential for rapid growth of the individual animal and as a measure of the maternal ability of the dam to raise the calf. Furthermore, many authors assert that birth weight is one of the most important factors, and often the most important one, that influence calving difficulty $[3,16$, 23-25]. Calving difficulty increases with an incline in birth weight, leading to a larger perinatal mortality [3]. Thus, the genetic evaluation of animals for productive traits like birth weight (BW), weaning weight (WW) or daily weight gain until weaning (DWG) have become very important for suckling herds. When calves are reared under different environmental conditions, either genetic evaluation by mixed models -BLUP- [13] or by within-herd selection indexes need the knowledge of non-genetic factors that influence the phenotypic value for unbiased predictions. This genetic evaluation requires that non-genetic causes of variation should be eliminated or reduced, and for smaller subclasses, such as sex, birth type or age of the dam, the usual procedure is to use correction factors $[10,15$, $26,30]$. These subclasses are consistent for all animals but cannot be fitted into genetic evaluation models because contemporary groups become small [37]. The main factors influencing birth and weaning traits are the sex of the calf, type of birth, region of origin, calving difficulty and age of the dam, year, and month of calving, among others $[10,20,28]$. If all these factors are fitted along with the genetic effects in the mixed model, the effective numbers of the contemporary groups may become severely reduced, causing biased predictions [33, 34]. By applying correction factors to predictable environmental factors, we can increase the effective numbers of the contemporary groups, and so reduce the bias of prediction.

Unfortunately, this situation is usually frequent regarding beef cattle populations. Bruna dels Pirineus is a representative example of beef breeds present in mountainous regions of Europe. In this context, this paper was an attempt to estimate appropriate correction factors to account for the environmental variability in a mountain beef cattle breed. Our results will contribute to the breeding scheme of the Bruna dels Pirineus; in addition they are an endeavour to revise and actualise the literature on correction factors for the beef cattle industry.

\section{MATERIALS AND METHODS}

After editing, the analysis was performed on 5925 birth weight (BW) records, 2608 standardised weaning weights (WW), and 2608 records of daily weight gain until weaning (DWG). Weaning weight was standardised to that of 185 days following the Beef Improvement Federation (BIF) formula [4]. The following factors were included in the analysis: a- sex of the calf $\left(\mathrm{S}_{\mathrm{j}}\right)$ : male or female; $\mathrm{b}$ - type of birth $\left(\mathrm{BT}_{\mathrm{k}}\right)$ : single or twins; $c$ - region of origin $\left(\mathrm{R}_{\mathrm{i}}\right)$, including 8 Catalonian regions: Ripollès, Cerdanya, Berguedà, Pallars Jussà, Alta Ribagorça, Solsonès, Osona and Pallars Sobirà; $\mathrm{d}-$ calving difficulty $\left(\mathrm{CD}_{1}\right)$, with two levels: $1-$ calving without difficulties (assisted or not), and 2- birth with difficulties or with a veterinarian's help; e- age of the dam at calving $\left(\mathrm{CA}_{\mathrm{m}}\right)$, including 6 intervals that followed in part the BIF [4] recommendations: 2- less than 1004 days of life, 
3- between 1004 and 1338 days, 4- between 1339 and 1703 days, 5- between 1704 and 2070 days, 6- between 2701 and 2436 days, $>6$ - more than 2436 days; $\mathrm{f}-$ month of calving $\left(\mathrm{M}_{\mathrm{n}}\right)$; g- year $\left(\mathrm{Y}_{\mathrm{o}}\right)$, including animals born between the years 1985 and 1997. The animals born during the period 1985-1987 were grouped into the same category $(<1988)$, because the effective number was small. Fixed effects that were not statistically significant were excluded from the final model. Interactions were not included because they led to poor significance levels and their inclusion implied the exclusion of two or more fixed effects.

After the elimination of factors that did not show statistical significance, the assumed operational models were:

$\mathrm{BW}_{\mathrm{ijkmnop}}=\mathrm{R}_{\mathrm{i}}+\mathrm{S}_{\mathrm{j}}+\mathrm{BT}_{\mathrm{k}}+\mathrm{CA}_{\mathrm{m}}+\mathrm{M}_{\mathrm{n}}$ $+\mathrm{Y}_{\mathrm{o}}+\mathrm{e}_{\mathrm{ijkmnop}}$

$\mathrm{WW}_{\mathrm{ijkmnop}}=\mathrm{R}_{\mathrm{i}}+\mathrm{S}_{\mathrm{j}}+\mathrm{BT}_{\mathrm{k}}+\mathrm{CA}_{\mathrm{m}}+\mathrm{M}_{\mathrm{n}}+\mathrm{Y}_{\mathrm{o}}$ $+\mathrm{e}_{\mathrm{ijkmnop}}$

$\mathrm{DWG}_{\mathrm{ijkmnop}}=\mathrm{R}_{\mathrm{i}}+\mathrm{S}_{\mathrm{j}}+\mathrm{BT}_{\mathrm{k}}+\mathrm{CA}_{\mathrm{m}}+\mathrm{M}_{\mathrm{n}}$ $+\mathrm{Y}_{\mathrm{o}}+\mathrm{e}_{\mathrm{ijkmnop}}$.

Only levels of significance of at least $P=0.01$ were accepted, because the errors were not distributed normally within all levels of each factor and also the heterogeneity of standard deviations appeared between the levels of some fixed effects [9].

Standard deviations for the levels of each fixed effect were calculated using the operational model without the implicated fixed effect. All levels of each fixed effect were analysed separately including only the records that had the level in question. The Generalised Linear Models procedure of SAS [29] calculates the Root MSE and this parameter estimates the standard deviation of the dependent variable [29].

It has been established that additive correction factors do not change standard deviations within the adjusted group, whereas multiplicative factors increase or reduce the variance in proportion to the square of the factor used, either larger or smaller than unity $[1,5,10,15,26]$. Thus, additive corrections will be better when within-level standard deviations are homogeneous, whereas a multiplicative correction will be indicated when the standard deviations differ significantly $[1,5,10,15,26]$. The heterogeneity of standard deviations was verified for each factor using a Bartlett [32] test or, when the fixed effect had two sublevels only, an F test $[32,38]$.

Additive correction factors for the levels of each fixed effect were estimated as the difference between the mean of each class and the mean of one of the classes which was arbitrarily fixed $[6,15,30]$. For the multiplicative correction, we followed a similar procedure, i.e., we calculated each factor as the ratio between the standard of the reference mean, that usually is the mean of the largest subclass $[6,15]$, and the mean of each one of the other subclasses. Therefore, we calculated the correction factors according to the following equations. Note that $A_{i}$ is the mean of the analysed variable for the " $i$ " subclass $(i=1,2, \ldots, n)$ of " $A$ " fixed effect, and $\overline{\mathrm{A}}_{1}$ is the standard of the reference mean.

\section{Additive correction Multiplicative correction factor (ACF) factor $(M C F)$}

$$
\begin{array}{cc}
\mathrm{ACF}_{1}=\overline{\mathrm{A}}_{1}-\overline{\mathrm{A}}_{1}=0 & \mathrm{MCF}_{1}=\overline{\mathrm{A}}_{1} / \overline{\mathrm{A}}_{1}=1 \\
\mathrm{ACF}_{2}=\overline{\mathrm{A}}_{1}-\overline{\mathrm{A}}_{2} & \mathrm{MCF}_{2}=\overline{\mathrm{A}}_{1} / \overline{\mathrm{A}}_{2} \\
\cdots & \cdots \\
\mathrm{ACF}_{\mathrm{n}}=\overline{\mathrm{A}}_{1}-\overline{\mathrm{A}}_{\mathrm{n}} & \mathrm{MCF}_{\mathrm{n}}=\overline{\mathrm{A}}_{1} / \overline{\mathrm{A}}_{\mathrm{n}} .
\end{array}
$$

When some of the factors did not show the same pattern of homogeneity or heterogeneity for all variables, we followed the procedure described by Cundiff et al. [10] and Izquierdo [15]. In this process, two new data bases were created, each of them including modified records according to one type of correction factor (additive or multiplicative). We subsequently assessed each correction factor in terms of the homogeneity of deviations of the corrected variables. 


\section{RESULTS}

A preliminary analysis of variables including all the factors allowed us to determine which fixed effects were appropriate. Note that the preliminary model for birth weight did not include the calving difficulty factor because, according to the literature, the cause-effect relation is inverse $[3,8,16$, 23-25]. There were differences among the levels of the factors for all variables except for calving difficulty (Tab. I). All traits were similarly affected by the known sources of variation $(P<0.01)$ (Tab. II). Males were heavier $(P<0.01)$ than females at birth and weaning, with a faster $(P<0.01)$ preweaning growth rate. Single calves were similarly heavier $(P<0.01)$ than twins. Both birth and weaning weight, as well as daily weight gain, increased until the cow reached maturity, at an age of 5 years.

Means for birth weight fluctuated without a clear tendency as far as the month of calving was considered. A marked decrease $(P<0.01)$ was found during July and August. The averages for weaning weight and daily weight gain showed a similar pattern, with a marked reduction $(P<0.01)$ in the calves born from April to July. No clear tendency was observed with regards to the year of calving.

Standard deviations were heterogeneous for the two sex levels (Tab. III). The multiplicative correction factor was regarded as the most appropriate (Tab. IV).
On the contrary, birth type showed homogeneity of standard deviations for the three analysed variables (Tab. III), so that the additive correction became preferable (Tab. IV). Values were calculated relative to figures for male and single calves.

Standard deviations within the levels of the age of the dam at calving were homogeneous for WW and DWG but heterogeneous for BW (Tab. III). It was not obvious which correction factor was appropriate for this fixed effect. Thus, we calculated the two possible correction factors, relative to the mean of calves born from more-than-6 year old cows $(>6)$ (Tab. V). In considering all the variables, the application of the additive correction factor was better, because the standard deviation of the estimated values of the residual standard deviations in every level was lower than when the multiplicative correction was applied. The differences between the standard deviations of age of the dam levels of each variable were statistically significant when compared through a Bartlett test, except for BW. Therefore, although the additive correction failed at homogenising the data completely, it was preferred to the multiplicative correction.

\section{DISCUSSION}

Productive traits of beef cattle like birth weight (BW), weaning weight (WW) or daily weight gain (DGW) are time correlated

Table I. Significance level of the different factors for birth weight (BW, kg), weaning weight (WW, $\mathrm{kg})$ and daily weight gain $\left(\mathrm{DWG}, \mathrm{kg} \cdot \mathrm{d}^{-1}\right)$.

\begin{tabular}{lccc}
\hline & BW & WW & DWG \\
\hline Region & $* * *$ & $* * *$ & $* * *$ \\
Sex & $* * *$ & $* * *$ & $* * *$ \\
Type of birth & $* * *$ & $* * *$ & $* *$ \\
Calving difficulty & & NS & NS \\
Age of dam & $* * *$ & $* * *$ & $* * *$ \\
Month of birth & $* * *$ & $* * *$ & $* * *$ \\
Year of birth & $* * *$ & $* * *$ & $* * *$ \\
\hline
\end{tabular}

NS: not significant; $* * P<0.01 ; * * * P<0.001$. 
Table II. Means of birth weight (BW), weaning weight (WW) and daily weight gain (DWG) for sex, type of birth and age of the dam at calving.

\begin{tabular}{|c|c|c|c|c|c|c|}
\hline & \multicolumn{2}{|c|}{$\mathrm{BW}, \mathrm{kg}$} & \multicolumn{2}{|c|}{ WW, kg } & \multicolumn{2}{|c|}{ DWG, $\mathrm{kg} \cdot \mathrm{d}^{-1}$} \\
\hline & $\mathrm{N}$ & Mean \pm SE & $\mathrm{N}$ & Mean \pm SE & $\mathrm{N}$ & Mean \pm SE \\
\hline General mean & 5925 & $44.8 \pm 0.1$ & 2608 & $233.3 \pm 0.5$ & 2608 & $1.017 \pm 0.002$ \\
\hline \multicolumn{7}{|l|}{ Sex } \\
\hline Male & 2891 & $46.3^{\mathrm{a}} \pm 0.1$ & 1267 & $242.6^{\mathrm{a}} \pm 0.7$ & 1267 & $1.059^{\mathrm{a}} \pm 0.004$ \\
\hline Female & 3034 & $43.4^{b} \pm 0.1$ & 1341 & $224.4^{b} \pm 0.6$ & 1341 & $0.978^{\mathrm{b}} \pm 0.003$ \\
\hline \multicolumn{7}{|l|}{ Birth type } \\
\hline Single & 5622 & $45.2^{\mathrm{a}} \pm 0.1$ & 2475 & $233.8^{a} \pm 0.5$ & 2475 & $1.018^{\mathrm{a}} \pm 0.003$ \\
\hline Twins & 303 & $36.7^{b} \pm 0.3$ & 133 & $223.0^{b} \pm 2.3$ & 133 & $1.002^{b} \pm 0.011$ \\
\hline \multicolumn{7}{|l|}{ Age of the dam } \\
\hline 2 & 305 & $40.8^{a} \pm 0.3$ & 108 & $208.0^{\mathrm{a}} \pm 2.3$ & 108 & $0.904^{\mathrm{a}} \pm 0.012$ \\
\hline 3 & 870 & $42.2^{b} \pm 0.2$ & 370 & $222.1^{b} \pm 1.3$ & 370 & $0.969^{\mathrm{b}} \pm 0.007$ \\
\hline 4 & 904 & $44.5^{c} \pm 0.2$ & 390 & $229.1^{c} \pm 1.3$ & 390 & $1.000^{c} \pm 0.007$ \\
\hline 5 & 791 & $45.8^{\mathrm{d}} \pm 0.2$ & 345 & $234.2^{\mathrm{d}} \pm 1.3$ & 345 & $1.018^{\mathrm{d}} \pm 0.007$ \\
\hline 6 & 684 & $46.0^{\mathrm{d}} \pm 0.2$ & 292 & $238.8^{d} \pm 1.3$ & 292 & $1.042^{\mathrm{d}} \pm 0.007$ \\
\hline$>6$ & 2371 & $45.6^{\mathrm{d}} \pm 0.1$ & 1103 & $239.1^{\mathrm{d}} \pm 0.7$ & 1103 & $1.044^{\mathrm{d}} \pm 0.004$ \\
\hline
\end{tabular}

Note: means with the same letter in the superscript do not differ significantly.

Table III. Heterogeneity of standard deviations within levels of traits.

\begin{tabular}{|c|c|c|c|}
\hline & $\mathrm{BW}, \mathrm{kg}$ & WW, kg & $\begin{array}{l}\text { DWG, } \\
\mathrm{kg} \cdot \mathrm{d}^{-1}\end{array}$ \\
\hline Sex & $* * *$ & $* *$ & $* * *$ \\
\hline Birth type & NS & NS & NS \\
\hline Age of dam & $*$ & NS & NS \\
\hline $\begin{array}{l}\text { NS: not } \\
* * * P<0.001 .\end{array}$ & cant; & $P<0.05$ & $* * P<0.01$ \\
\hline \multicolumn{4}{|c|}{$\begin{array}{l}\text { measures when the dam influence is con- } \\
\text { sidered, because they contain a common } \\
\text { contribution from the same animal. Then, } \\
\text { these variables can be studied with a repeated } \\
\text { measures analysis }[7,21] \text { considering that, } \\
\text { in most cases, each dam contributes various } \\
\text { calves to the analysis and the records of } \\
\text { these brothers are correlated. The dam ef- } \\
\text { fect, which implies a random source of vari- } \\
\text { ation, was considered initially, but later } \\
\text { mixed models were rejected due to impor- }\end{array}$} \\
\hline
\end{tabular}

Table IV. Correction factors for sex of the calf and birth type regarding birth weight (BW), weaning weight (WW), and daily weight gain (DWG).

\begin{tabular}{lrrr}
\hline \multicolumn{1}{l}{ BW } & WW & DWG \\
\hline \multicolumn{2}{l}{ Multiplicative factors } \\
Sex & & \\
Male & 1.000 & 1.000 & 1.000 \\
Female & 1.067 & 1.081 & 1.083
\end{tabular}

Additive corrections

Type of birth

\begin{tabular}{lrrr} 
Single & 0.000 & 0.000 & 0.000 \\
Twins & 8.553 & 10.790 & 0.016 \\
\hline
\end{tabular}

tant incompatibilities with the structure of our data base. An important percentage of our dams contributed only one calf $(33.0 \%$ in BW, and $41.5 \%$ in WW and DGW). This implies that the measures of all these only sons were not correlated with other records, and this data base structure, with many uncorrelated 
Table V. Additive and multiplicative corrections for age of dam (2 - >6 years), and standard deviations regarding birth weight (BW), weaning weight (WW) and daily weight gain (DWG).

\begin{tabular}{cccc}
\hline & BW & WW & DWG \\
\hline Multiplicative factors & & & \\
2 & 1.119 & 1.150 & 1.155 \\
3 & 1.077 & 1.077 & 1.077 \\
4 & 1.024 & 1.044 & 1.044 \\
5 & 1.000 & 1.000 & 1.000 \\
6 & 1.000 & 1.000 & 1.000 \\
$>6$ & 1.000 & 1.000 & 1.000
\end{tabular}

Additive correction

$\begin{array}{lrrr}2 & 4.824 & 31.127 & 0.140 \\ 3 & 3.255 & 17.023 & 0.074 \\ 4 & 1.143 & 9.995 & 0.045 \\ 5 & 0.000 & 0.000 & 0.000 \\ 6 & 0.000 & 0.000 & 0.000 \\ >6 & 0.000 & 0.000 & 0.000\end{array}$

Standard deviation

$\begin{array}{llll}\text { Additive correction } & 0.199 & 1.083 & 0.005\end{array}$

Multiplicative

$\begin{array}{llll}\text { correction } & 0.462 & 2.120 & 0.012\end{array}$

records, implied biases when residual standard deviations were estimated. On the other hand, least square means are claimed to be preferable when the design is unbalanced [29] but in our data base, the animals with poor weights and growths were over-represented because they were distributed across all sublevels of each fixed effect whereas the heavier calves were grouped into a few sublevels. As a consequence, all least square mean estimates were lower than the overall arithmetic mean. For these reasons, we decided to assume fixed models. According to several studies $[2,14,21]$, the standard errors from models that ignore random effects were smaller than the mixed models and then, they probably were underestimated.

According to the results of a preliminary analysis of variables including all the factors, only birth difficulty did not arrive to the $P=0.01$ significance level for all variables. This fact suggests that some birth problems would not affect the subsequent growth of the calf. On the other hand, although the type of birth significantly influenced all variables, the major part of the differences observed in WW between calves coming from single and double births originated in differences in birth weight. This fact emphasises the excellent maternal ability of the Bruna dels Pirineus cow that is capable of coping with the rearing of two calves at a time with high DWG. This maternal ability reached its maximum when the cow was 5 years old (mature age). Furthermore, the other two analysed variables also increased until the cow reached maturity. Similar results for birth weight have been described by Sierra [31] in Spanish Brown Swiss cattle before being selected for milk production, Villalba et al. [36] in the Brown Swiss and Pirenaica, and Benyshek et al. [3] in the Simmental. The increase of birth weight until the dam attains maturity has also been documented in Simmental calves [3], Limousine calves [22], Suffolk lambs [15], and South African Mutton Merino and Dormer lambs [8]. Weaning weight and daily weight gain were comparable with the results obtained in the Spanish Brown Swiss [31], and Brown Swiss and Pirenaica [36]. Various authors have also observed the increase of weaning weight until the dam reaches maturity [3, $10,15,20]$.

The levels of the sex of the calf showed heterogeneous standard deviations, which were comparable to the results of several studies in beef cattle $[1,5,10,11,18,19$, $26,27,35]$ and in sheep [15]. On the contrary, the additive correction factor was preferable for birth type.

The standard deviations of the levels of cow age were either homogeneous or heterogeneous depending upon the traits studied. Similar results have been described in Hereford and Angus cattle [10], and in Suffolk lambs [15]. According to the results of Table V, the additive correction was better, although some heterogeneity of standard 
deviations may still remain. These conclusions are comparable to the results obtained by diverse authors in bovine and ovine livestock $[1,10,15,26]$.

\section{REFERENCES}

[1] Anderson J.H., Willham R.L., Weaning weight correction factors from Angus field data, J. Anim. Sci. 47 (1978) 124-130.

[2] Barkhouse L.D., Van Vleck L.D., Cundiff L.V., Effect of ignoring random sire and dam effects on estimates and standard errors of breed comparisons, J. Anim. Sci. 76 (1998) 2279-2286.

[3] Benyshek L.L., Little D.E., Estimates of genetic and phenotypic parameters associated with pelvic area in Simmental cattle, J. Anim. Sci. 54 (1982) 258-263.

[4] BIF, Beef Improvement Federation Guidelines, North Carolina: North Carolina University Press, 1986.

[5] Brinks J.S., Clark R.T., Rice F.J., Kieffer N.M., Adjusting birth weight, weaning weight, and daily gain weight for sex of calf in range Hereford cattle, J. Anim. Sci. 20 (1961) 363-367.

[6] Cardellino R., Frahm R.R., Evaluation of two types of age of dam correction factors for weaning weight in beef cattle, J. Anim. Sci. 32 (1971) 1078-1083.

[7] Carta A., Macciotta N.P.P., Cappio-Borlino A., Sanna S.R., Modelling phenotypic (co)variances of test day records in dairy ewe, Livest. Prod. Sci. 69 (2001) 9-16.

[8] Cloette S.W.P., Scholtz A.J., Ten Hoope J.M., Lombard P.J.A., Franken M.C., Ease of birth relation of pelvic dimensions, litter weight and conformation of sheep, Small Ruminant Res. 31 (1998) 51-60.

[9] Cochran W.G., Cox G.M., Experimental designs, John Wiley \& Sons, New York, 1957.

[10] Cundiff L.V., Willham R.L., Pratt C.A., Additive versus multiplicative correction factors for weaning weight in beef cattle, J. Anim. Sci. 25 (1966) 983-987.

[11] Garrick D.J., Pollak E.J., Quaas R.L., Van Vleck L.D., Variance heterogeneity in direct and maternal weight traits by sex and percent pure-bred for Simmental-sired calves, J. Anim. Sci. 67 (1989) 2515-2528.

[12] Groeneveld E., Mostert B.E., Rust T., The covariance structure of growth traits in the Afrikaner beef population, Livest. Prod. Sci. 55 (1998) 99-107.

[13] Henderson C.R., Sire evaluation and genetic trends, Proceedings of the animal breeding and genetics symposium in honor of Jay L. Lush., ASAS and ADSA, 1973, pp. 10-41.
[14] Hirooka H., Groen A.F., Van der Werf J.H.J., Estimation of additive and non-additive genetic parameters for carcass traits on bulls in dairy, dual purpose and beef cattle breeds, Livest. Prod. Sci. 54 (1998) 99-105.

[15] Izquierdo M., Nongenetic adjustment factors for lamb weaning weight in the Suffolk breed, M.Sc. Thesis, Iowa State University, Iowa, 1991

[16] Johnson S.K., Deutscher G.H., Parkhurst A., Relationship of pelvic structure, body measurements, pelvic area and calving difficulty, J. Anim. Sci. 66 (1988) 1081-1088.

[17] Koots K.R., Gibson J.P., Smith C., Wilton J.W., Analyses of published genetic parameter for beef production traits. 1. Heritability, Anim. Breed. Abstr. 62 (1994) 309-338.

[18] Lee C., Pollak E.J., Influence of partitioning data by sex on genetic variance and covariance components for weaning weight in beef cattle, J. Anim. Sci. 75 (1997) 61-67.

[19] Lee C., Van Tassell C.P., Pollak E.J., Estimation of genetic variance and covariance components for weaning weight in Simmental cattle, J. Anim. Sci. 75 (1997) 325-330.

[20] Leighton E.A., Willham R.L., Berger P.J., Factors influencing weaning weight in Hereford cattle and adjustment factors to correct records for these effects, J. Anim. Sci. 54 (1982) 957-963.

[21] Littell R.C., Henry P.R., Ammerman C.B., Statistical analysis of repeated measures data using SAS procedures, J. Anim. Sci. 76 (1998) 12161231.

[22] Massey M.E., Benyshek L.L., Estimates of genetic and environmental effects on performance traits from Limousine field data, J. Anim. Sci. 52 (1981) 37-43.

[23] Meijering A., Dystocia and stillbirth in cattle - A review of causes, relations and implications, Livest. Prod. Sci. 11 (1984) 143-177.

[24] Menissier F., Vissac B., Possibilités d'amélioration des conditions de vélage par selection. 1. Technique de mesure de l'ouverture pelvienne des bovins, Ann. Génét. Sél. Anim. 8 (1971) 207 214.

[25] Naazie A., Makarechian M., Berg R.T., Genetic, phenotypic, and environmental parameter estimates of calving difficulty, weight, and measures of pelvic size in beef heifers, J. Anim. Sci. 69 (1991) 4793-4800

[26] Nelsen T.C., Kress D.D., Additive and multiplicative correction factors for sex and age of dam in beef cattle weaning weight, J. Anim. Sci. 53 (1981) 1217-1224.

[27] Rodríguez-Almeida F.A., Van Vleck L.D., Cundiff L.V., Kachman S.D., Heterogeneity of variance by sire breed, sex, and dam breed in 200- and 365-day weights of beef cattle from a top cross experiment, J. Anim. Sci. 73 (1995) 2579-2588. 
[28] Rossi D.J., Kress D.D., Tess M.W., Bufening P.J., Correcting bias from the standard linear adjustment of weaning weight to an age-constant basis for beef calves, J. Anim. Sci. 70 (1992) 13331341.

[29] SAS, SAS/STAT ${ }^{\circledR}$ User's Guide, SAS Institute Inc., Cary, NC, 1992.

[30] Schaeffer L.R., Notes on linear model theory and Henderson's mixed model techniques, University of Guelph: Mimeo, 1979.

[31] Sierra I., in: Ocaña M. (Ed.), Ensayo de Planificación Ganadera en Aragón, Institución "Fernando el Católico", 1978, pp. 165-239.

[32] Snedecor G., Cochran W., Statistical methods, Iowa State University Press, Ames, Iowa, 1989.

[33] Ugarte E., Alenda R., Carabaño M.J., Fixed or random contemporary groups in genetic evaluations, J. Anim. Sci. 75 (1991) 269-278.

[34] van Bebber J., Reinsch N., Junge W., Kalm E., Accounting for herd, year and season effects in genetic evaluations of dairy cattle: a review, Livest. Prod. Sci. 51 (1997) 191-203.

[35] Varona L., Aplicaciones del muestreo de Gibbs en modelos de genética cuantitativa: Análisis de un caso de heterogeneidad de varianzas, Tesis Doctoral, Universidad de Zaragoza, Zaragoza, 1994.

[36] Villalba D., Casasús I., Sanz A., Estany J., Revilla R., Preweaning growth curves in Brown Swiss and Pirenaica calves with emphasis on individual variability, J. Anim. Sci. 78 (2000) 1132-1140.

[37] Wilson D.E., Rothschild M.F., Boggess M.V., Morrical D.G., Adjustment factors for birth weight and 30-day, 60-day, and 90-day weaning weight in sheep, J. Anim. Breed. Genet. 133 (1996) 29-41.

[38] Zar J.H., Biostatistical analysis, Prentice Hall International Editions, London, 1996. 